(6)

\title{
Fondaparinux and acute coronary syndromes: update on the OASIS 5-6 studies
}

This article was published in the following Dove Press journal:

Vascular Health and Risk Management

24 March 2010

Number of times this article has been viewed

\section{François Schiele \\ Department of Cardiology, University Hospital Jean-Minjoz, Besançon, France}

\begin{abstract}
Anticoagulant therapy is a major component in the management of acute coronary syndromes (ACS). Four anticoagulant agents are currently commercially available for ACS, namely unfractionated heparin (UFH), enoxaparin, bivalirudin and fondaparinux. We describe the advantages of fondaparinux and the reasons that have hampered its uptake into routine management of ACS. Fondaparinux was shown to be efficacious in the prevention of deep vein thrombosis vs low-molecular-weight heparins, while in the setting of venous thrombo-embolic disease, it was shown to be noninferior to enoxaparin and UFH. Two pivotal studies have demonstrated the efficacy of fondaparinux as an anticoagulant in the setting of ACS, namely OASIS-5 in non-ST elevation ACS, and OASIS-6 in ST elevation myocardial infarction (MI). In OASIS-5, fondaparinux was shown to be noninferior to enoxaparin in terms of death, MI or refractory ischemia at 9 days. Furthermore, a 50\% reduction in bleeding complications was obtained with fondaparinux vs enoxaparin, leading to a risk reduction for death. In OASIS-6, fondaparinux was shown to be superior to the comparator (UFH or placebo). European and North American guidelines give fondaparinux a Grade 1A and 1B recommendation respectively, but uptake of fondaparinux in routine practice has been slow. We explore reasons for this, such as prevailing doubts about the efficacy of fondaparinux in the setting of angioplasty, the problem of catheter thrombosis, and the lack of antidote in case of bleeding complications. With the exception of primary angioplasty, fondaparinux is as effective as enoxaparin or UFH, but is also associated with a considerable reduction in bleeding complications, and thus, an undeniable net clinical benefit.
\end{abstract}

Keywords: fondaparinux, OASIS, acute coronary syndromes

\section{Introduction}

Anticoagulant therapy is the one of the cornerstones in the management of acute coronary syndromes (ACS), in both invasive and noninvasive strategies. ${ }^{1,2}$ Currently, four anticoagulant agents are commercially available for the treatment of ACS, namely, unfractionated heparin (UFH), enoxaparin, bivalirudin, and fondaparinux (pentasaccharide). Each of these agents has its different advantages and disadvantages, and there are also differing levels of evidence supporting the efficacy and safety of each. In the two years since fondaparinux has become commercially available, its place in the management of ACS remains minor, as shown by the results of the Euro Heart Survey ACS-3 registry. This article aims to describe the advantages of fondaparinux, both theoretical and proven, as well as the reasons why its uptake into routine management of ACS has been moderate.

\section{Anticoagulants available in the context of ACS}

UFH remains the most frequently used anticoagulant agent in the setting of ACS. It has both anti-IIa and anti-Xa effects, and apart from being inexpensive, its further advan- 
tages are that it is not contra-indicated in case of severe renal insufficiency, it has a short half-life, and it can be neutralized if necessary using protamine sulfate. The main disadvantage of UFH is that its action is neither stable nor predictable, with the result that frequent monitoring and dose adjustments are necessary, even with intravenous use.

Low-molecular-weight heparins (LMWH), such as enoxaparin, have an excellent bioavailability, preferential anti-Xa activity, and can be used by intravenous or subcutaneous route. They have been shown to be superior to UFH in case of "conservative" management strategy $y^{3,4}$ or in the setting of ST elevation myocardial infarction (STEMI) treated by thrombolytic therapy. ${ }^{5}$ In the setting of non-ST elevation ACS (NSTE-ACS) submitted to angioplasty, enoxaparin has comparable efficacy to UFH, but with more frequent hemorrhagic complications ${ }^{6}$ and has never been tested in the setting of primary angioplasty for STEMI.

Bivalirudin represents a third group of anticoagulant agents, namely direct thrombin inhibitors. Bivalirudin can be administered intravenously, has a predictable efficacy, a very short half-life, and no interaction with platelet function. All these qualities make bivalirudin an attractive alternative for use in the setting of angioplasty. Two large randomized trials have compared bivalirudin to a combination of UFH and antiGP IIb/IIIa inhibitors, and showed that efficacy was similar, with fewer bleeding events under bivalirudin therapy in the setting of NSTE-ACS, ${ }^{7}$ and a reduction in mortality in the setting of STEMI treated by primary angioplasty. ${ }^{8}$

Lastly, fondaparinux is a synthetic pentasaccharide that reproduces the sequence in heparins that mediates their interaction with antithrombin. It has a pure and selective anti-Xa activity through its link with antithrombin. The inhibition of thrombin generation is dose-dependent, but without inhibiting the actual thrombin molecule. The mechanism of action of fondaparinux is unique, in that the fondaparinux molecule attaches itself to the antithrombin, thereby changing its structure and allowing the neutralization of factor Xa. After inhibition of one factor Xa molecule, the fondaparinux is released in its active form by the antithrombin, and can thus recirculate and attach to another antithrombin molecule to perform another round of inhibition of factor Xa. This cycle serves to amplify the effect of fondaparinux. Compared to UFH, the affinity of fondaparinux for antithrombin is 15 times higher, and the inhibition of thrombin generation is considerably increased through the anti-Xa activity. ${ }^{9}$ The bioavailability of fondaparinux is $100 \%$ after subcutaneous injection, and its half-life is around 17 hours. Since it is eliminated primarily through the renal route, it is insensitive to inactivation by platelet proteins, which neutralise heparin. It causes no formation of heparin-PF4 complexes, and does not expose the patient to a risk of heparin-induced thrombocytopenia.

\section{Studies of fondaparinux in the setting of ACS}

Fondaparinux was shown to be efficacious in the prevention of deep vein thrombosis in the setting of major orthopedic surgery compared with usual therapy with LMWH. ${ }^{10,11}$ In the setting of venous thrombo-embolic disease, deep vein thrombosis, or pulmonary embolism, fondaparinux was shown to be noninferior to enoxaparin and UFH, respectively. On the arterial side, the anticoagulant efficacy of fondaparinux was demonstrated in a pilot study using primary angioplasty as a model of arterial thrombosis. ${ }^{12}$ Phase II studies were carried out in both forms of ACS, namely STEMI ${ }^{13}$ and NSTE-ACS. ${ }^{14}$ In this latter study, the $2.5 \mathrm{mg}$ once-daily dose was shown to have superior efficacy than higher doses of fondaparinux and enoxaparin, with a lower rate of bleeding. The $2.5 \mathrm{mg}$ dose was then selected for use in phase III randomized trials in ACS with and without ST elevation. The two pivotal studies of fondaparinux in this setting were OASIS-5, ${ }^{15}$ which included 20,078 patients with NSTE-ACS, and OASIS-6, ${ }^{16}$ which included 12,092 patients with STEMI. In OASIS-5, fondaparinux was shown to be noninferior to enoxaparin in terms of the main efficacy endpoints (death, $\mathrm{MI}$, refractory ischemia) at 9 days. More importantly, a reduction of almost $50 \%$ in bleeding complications was obtained with fondaparinux compared with enoxaparin ( $2.2 \%$ vs $4.1 \%$ respectively). This reduction in bleeding had a considerable effect on the rate of ischemic events, with a significant reduction in death at 30 days and 6 months, but also with significant reductions in the combined endpoints of death/MI and death/MI/stroke at 30 days and 6 months. It is important to underline that this benefit was observed in all the predefined subgroups, in particular among the elderly, females, patients with renal failure, diabetes patients, and also in all risk categories (low, medium, and high risk). Finally, and perhaps most important of all, the benefit was consistent in patients submitted to coronary angioplasty, in whom fondaparinux was shown to be noninferior at 9 days compared with enoxaparin in terms of the main efficacy endpoint, but with a considerable reduction in bleeding complications. As a result, the net clinical benefit is significantly greater with fondaparinux than with enoxaparin.

In the overall population of the OASIS-6 study, fondaparinux was shown to be superior to the comparator 
(UFH or placebo). In OASIS-6, patients were randomized to two strata, depending on whether heparin was indicated or not (in stratum 1, the comparator was placebo and in stratum 2, the comparator was UFH). Not only was a reduction in mortality or re-infarction observed with fondaparinux (7.4\% vs $8.9 \%, P=0.003$ at 9 days, $9.7 \%$ vs $11.2 \%, P=0.008$ at 30 days and $13.4 \%$ vs $14.8 \%, P=0.008$ at 6 months), but there was also a reduction in mortality $(6.1 \%$ vs $7.0 \%$, $P=0.04$ at 9 days, $7.8 \%$ vs $8.9 \%, P=0.03$ at 30 days and $10.5 \%$ vs $11.6 \%, P=0.03$ at 6 months). In parallel, there was a trend towards fewer major bleedings, and significantly less tamponnade in the fondaparinux group. These results showing a reduced ischemic risk without an increase in bleeding risk were observed in patients who were not reperfused, in patients submitted to thrombolytic therapy, but not in patients treated by primary angioplasty.

\section{The place of fondaparinux in European and North American guidelines}

Since the results of the OASIS-5 and OASIS- 6 studies were reported, the guidelines for the management of STEMI ${ }^{17}$ and NSTE-ACS ${ }^{1,18,19}$ issued by the ESC, ACC-AHA and ACCP have all been updated. Although based on the same scientific evidence, the levels of recommendation in the ESC and American guidelines are not exactly the same, because different criteria were taken into consideration to decide on the level of recommendation (Table 1).

In the guidelines issued by the ESC and the ACCP, fondaparinux enjoys a grade $1 \mathrm{~A}$ recommendation in the setting of NSTE-ACS, except in case of urgent angioplasty. The ACC-AHA guidelines give a grade 1A recommendation for fondaparinux in case of conservative strategy, but grade $1 \mathrm{~B}$ in case of invasive strategy, and do not make any distinction with urgent angioplasty. In the setting of STEMI, fondaparinux is recommended over no anticoagulation, in patients not undergoing reperfusion, in case of thrombolytic therapy, but not in case of primary angioplasty (Figure 1). The ACCP recommendations largely follow those of the ESC, recommending against the use of fondaparinux in case of primary angioplasty. In case of angioplasty in patients pretreated with fondaparinux, an additional bolus of 50 to $100 \mathrm{IU} / \mathrm{kg}$ of UFH is recommended.

Finally, the ESC guidelines for the management of NSTE-ACS accord particular attention to patients at high risk of bleeding, namely women, elderly patients, patients with renal failure and those with baseline anemia. The use of fondaparinux is recommended in these groups on the basis of its superior efficacy-safety profile.

\section{Barriers to the use of fondaparinux in ACS}

Despite the favorable results of the OASIS-5 and 6 trials and the strong recommendations of the European and North American guidelines, which give fondaparinux a grade IA or IB recommendation in NSTE-ACS, the use of fondaparinux in this setting has not been as high as might be expected, particularly in centers with angioplasty facilities on site. The Euro Heart Survey ACS III registry shows that fondaparinux is used in only $3 \%$ of patients, compared with $43 \%$ for UFH and $53 \%$ for enoxaparin. To date, there has been only one study reporting the routine use of fondaparinux in ACS. In a multicenter registry of over 2800 patients, the uptake of fondaparinux in routine practice 2 years after its first availability on the market reportedly depends heavily on local factors. Centers with cathlabs on site were reluctant to use fondaparinux routinely, preferring UFH or enoxaparin ${ }^{20}$ (Figure 2). The reasons for this choice are manifold, and include prevailing doubts about the efficacy of fondaparinux in the setting of angioplasty, the problem of catheter thrombosis, and the lack of antidote in case of bleeding complications.

\section{Angioplasty under fondaparinux therapy}

- The efficacy and safety of fondaparinux in ACS (STEMI or NSTE-ACS) has been studied in a pooled analysis of the OASIS- 5 and 6 data. ${ }^{21}$ In patients who underwent invasive strategy, fondaparinux reduced mortality at 30 days, the combined endpoint (death, MI, or stroke), and major bleeding, compared with UFH or enoxaparin.

- In NSTE-ACS, results from angioplasty under fondaparinux therapy were studied in the OASIS-5 trial, in which $64 \%$ of patients underwent invasive diagnostic exam during the treatment phase, and 31\% (6238) underwent angioplasty within the first 72 hours. This predefined subgroup of patients with invasive strategy was analyzed separately. ${ }^{22}$ In this situation, the benefit obtained with fondaparinux compared with enoxaparin was similar to that observed in the main cohort, insofar as the rate of ischemic events was identical at 9 days, and there was a significant reduction in major bleeding $(1.6 \%$ vs $3.8 \%$, hazard ration $[\mathrm{HR}] 0.42, P<0.001)$. Furthermore, the net clinical benefit was superior with fondaparinux (rate of death, infarction, stroke or major bleeding at 9 days of 
Table I Classes of recommendations and levels of evidence according to the ESC and ACC/AHA guidelines ${ }^{1,2}$

\begin{tabular}{|c|c|c|}
\hline $\begin{array}{l}\text { Classes of } \\
\text { recommendations }\end{array}$ & ESC & ACC/AHA \\
\hline Class I & $\begin{array}{l}\text { Evidence and/or general agreement that } \\
\text { a given treatment or procedure is beneficial, } \\
\text { useful and effective }\end{array}$ & $\begin{array}{l}\text { Benefit }>>>\text { Risk } \\
\text { Procedure/treatment should } \\
\text { be performed }\end{array}$ \\
\hline Class II & $\begin{array}{l}\text { Conflicting evidence and/or divergence } \\
\text { of opinion about the usefulness/efficacy } \\
\text { of a given treatment procedure }\end{array}$ & - \\
\hline Class Ila & $\begin{array}{l}\text { Weight of evidence/opinion is in favor } \\
\text { of usefulness/efficacy }\end{array}$ & $\begin{array}{l}\text { Benefit }>>\text { Risk } \\
\text { Additional studies with focused objectives needed } \\
\text { It is reasonable to perform procedure/administer } \\
\text { treatment }\end{array}$ \\
\hline Class Ilb & $\begin{array}{l}\text { Usefulness/efficacy is less well established } \\
\text { by evidence/opinion }\end{array}$ & $\begin{array}{l}\text { Benefit } \geq \text { Risk } \\
\text { Additional studies with broad objectives needed; } \\
\text { additional registry data would be helpful } \\
\text { Procedure/treatment may be considered }\end{array}$ \\
\hline Class III & $\begin{array}{l}\text { Evidence or general agreement that the } \\
\text { given treatment or procedure is not useful/ } \\
\text { effective and in some cases may be harmful }\end{array}$ & $\begin{array}{l}\text { Risk } \geq \text { Evidence } \\
\text { No additional studies needed } \\
\text { Procedure/treatment should not be performed/ } \\
\text { administered since it is not helpful and may be } \\
\text { harmful }\end{array}$ \\
\hline \multicolumn{3}{|l|}{ Levels of evidence } \\
\hline A & $\begin{array}{l}\text { Data derived from multiple randomized } \\
\text { clinical trials or meta-analyses }\end{array}$ & $\begin{array}{l}\text { Multiple (3-5) population risk strata evaluated } \\
\text { General consistency of direction and magnitude of effect }\end{array}$ \\
\hline B & $\begin{array}{l}\text { Data derived from a single randomized } \\
\text { clinical trial or large nonrandomized studies }\end{array}$ & Limited (2-3) population risk strata evaluated \\
\hline C & $\begin{array}{l}\text { Consensus of opinion of the experts and/or } \\
\text { small studies, retrospective studies, registries }\end{array}$ & Very limited $(I-2)$ population risk strata evaluated \\
\hline
\end{tabular}

Abbreviations: ESC, European Society of Cardiology; ACC/AHA,American College of Cardiology/American Heart Association.

$8.2 \%$ vs $10.4 \%, \mathrm{HR}=0.78, P=0.004)$ (Table 2$)$. Thus, in the context of an early invasive strategy, the results plead in favor of fondaparinux. It is noteworthy that the reduction in bleeding complications appeared very early, with a reduction of $35 \%$ to $40 \%$ from day 1 to day 8 (Table 3 ).

- In the setting of STEMI, the results of OASIS- 6 are also globally in favor of fondaparinux. In stratum II of this study (ie, compared to patients treated with UFH), the rate of ischemic events was not significantly different between treatment arms. However, in the group of patients who underwent primary angioplasty, there was a tendency towards an excess of death at 30 days (6.1\% with fondaparinux vs $5.1 \%$ with UFH, $P=0.19)$ (Figure 1 and 3 ). Although this trend was not significant at 30 days, and was not observed at all at the other timepoints (9 days and 6 months), it could explain why fondaparinux is not recommended for use in primary angioplasty in the setting of STEMI. ${ }^{17,23}$ Conversely, in the population of 2666 patients with STEMI who underwent angioplasty other than by primary percutaneous coronary intervention
(PCI), outcome was favorable under fondaparinux therapy compared with UFH (rate of death or infarction of $11.5 \%$ vs $13.8 \%$ respectively, $P=0.08$ ), with a trend towards fewer major bleeding events.

\section{The occurrence of catheter thrombus}

This is a second element that may explain the reluctance of certain interventional cardiologists to use fondaparinux in angioplasty.

- Although it was not one of the predefined endpoints, the OASIS-5 and -6 investigators reported several occurrences of catheter thrombus with fondaparinux. This problem had not been encountered during the pilot dose-finding study for fondaparinux, ${ }^{14}$ but in OASIS-5, although the rate of coronary occlusion was comparable in both arms, the rate of catheter thrombus was higher with fondaparinux than with enoxaparin $(0.9 \%$ vs $0.4 \%, P<0.001)$. This was confirmed versus UFH in OASIS-6 in the setting of primary angioplasty 


\section{No. (\%) of Patients with events}

\begin{tabular}{|c|c|c|c|}
\hline $\begin{array}{l}\text { Characteristic } \\
\text { Stratum }\end{array}$ & $\begin{array}{c}\text { No.of } \\
\text { Patients }\end{array}$ & UFH or Placebo & Fondaparinux \\
\hline $\begin{array}{l}\text { UFH Not indicated } \\
\text { UFH Indicated }\end{array}$ & $\begin{array}{l}5658 \\
6434\end{array}$ & $\begin{array}{l}396(14.0) \\
281(8.7)\end{array}$ & $\begin{array}{l}317(11.2) \\
268(8.3)\end{array}$ \\
\hline $\begin{array}{l}\text { Time from onset to ran } \\
<3 \\
3 \text { to }<6 \\
6 \text { to }<12 \\
\geq 12\end{array}$ & $\begin{array}{l}3008 \\
4300 \\
3290 \\
1460\end{array}$ & $\begin{array}{l}141(9.5) \\
224(10.3) \\
218(13.3) \\
92(12.5)\end{array}$ & $\begin{array}{l}110(7.2) \\
203(9.6) \\
196(11.9) \\
73(10.1)\end{array}$ \\
\hline $\begin{array}{l}\text { Initial Reperfusion Th } \\
\text { None } \\
\text { Thrombolytic } \\
\text { Primary PCl }\end{array}$ & $\begin{array}{l}2867 \\
5436 \\
3789\end{array}$ & $\begin{array}{l}212(15.1) \\
372(13.6) \\
93(4.9)\end{array}$ & $\begin{array}{l}178(12.2) \\
293(10.9) \\
114(6.0)\end{array}$ \\
\hline $\begin{array}{l}\text { Sex } \\
\text { Female } \\
\text { Male }\end{array}$ & $\begin{array}{l}3345 \\
8746\end{array}$ & $\begin{array}{l}287(16.9) \\
390(9.0)\end{array}$ & $\begin{array}{l}246(15.0) \\
339(7.7)\end{array}$ \\
\hline $\begin{array}{l}\text { Age, y } \\
<62 \\
\geq 62\end{array}$ & $\begin{array}{l}5980 \\
6106\end{array}$ & $\begin{array}{l}170(5.6) \\
507(16.8)\end{array}$ & $\begin{array}{l}149(5.1) \\
436(14.1)\end{array}$ \\
\hline $\begin{array}{l}\text { GRACE score } \\
\quad<112 \\
\geq 112\end{array}$ & $\begin{array}{l}5958 \\
6134\end{array}$ & $\begin{array}{l}130(4.3) \\
547(18.0)\end{array}$ & $\begin{array}{l}136(4.6) \\
449(14.5)\end{array}$ \\
\hline $\begin{array}{l}\text { Prerandomization UF } \\
\text { No } \\
\text { Yes }\end{array}$ & $\begin{array}{r}10304 \\
1787\end{array}$ & $\begin{array}{l}609(11.8) \\
68(7.7)\end{array}$ & $\begin{array}{l}527(10.3) \\
58(6.4)\end{array}$ \\
\hline Overall & 12092 & $677(11.2)$ & 585 (9.7) \\
\hline
\end{tabular}

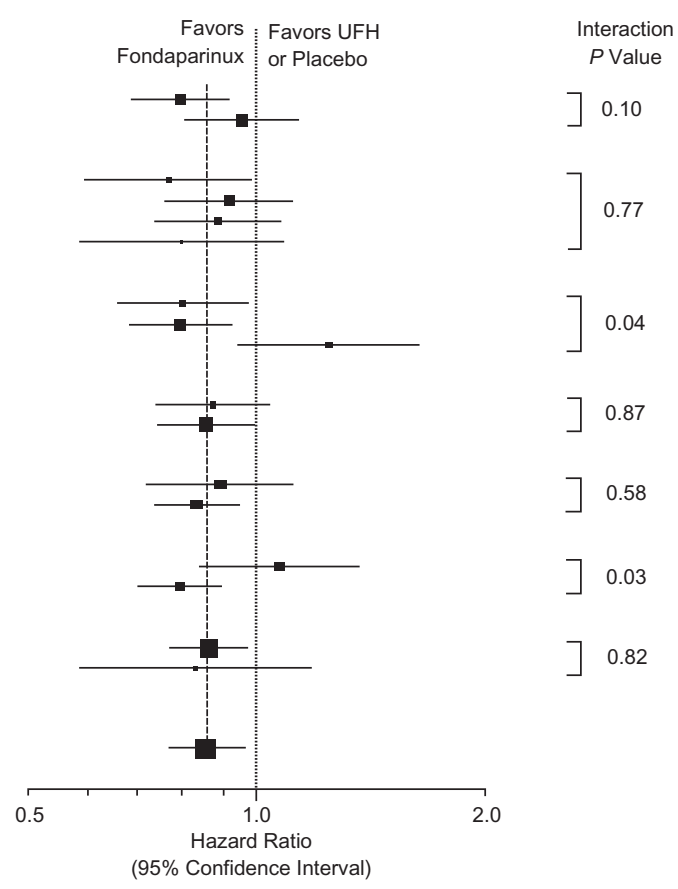

Figure I Rates of death and myocardial infarction in prespecified subgroups at 30 days in the OASIS-6 trial. Reproduced with permission from Yusuf S, Mehta SR, Chrolavicius S, et al. Effects of Fondaparinux, on mortality and reinfarction in patients with acute ST-segment elevation mycardial infarction: the OASIS-6 randomized trial. JAMA. 2006;295(13):1519-1530.16 Copyright (C) 2006 American Medical Association.
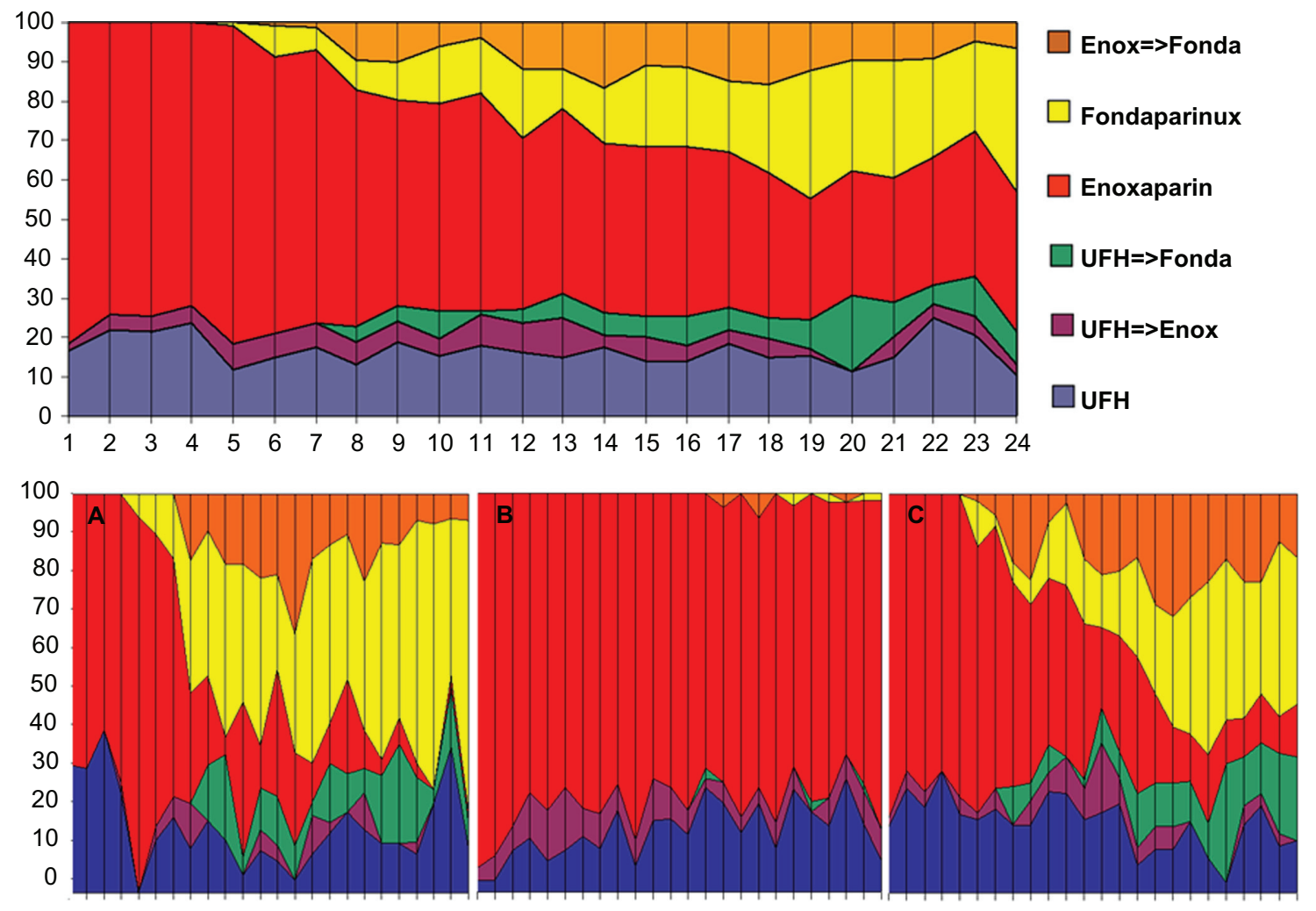

Figure 2 Monthly rate of use of unfractionated heparin, enoxaparin and fondaparinux in the whole population and by type of center (A: University center with cath lab facilities on site, B: community centers with cath lab on site, C: community centers without cath lab on site). Reproduced with permission from Schiele F, Meneveau N, Seronde MF, et al. Routine use of fondaparinux in acute coronary syndromes: a 2-year multicenter experience. Am Heart J. 2010;159(2):190-198. ${ }^{20}$ Copyright $@ 2010$ Elsevier. 
Table 2 Clinical outcomes at day 9 in patients undergoing $\mathrm{PCl}$ in OASIS-5

\begin{tabular}{|c|c|c|c|c|}
\hline All $\mathrm{PCl}$ patients & $\begin{array}{l}\text { Fondaparinux } \\
\mathbf{N}=3105\end{array}$ & $\begin{array}{l}\text { Enoxaparin } \\
\mathbf{N}=\mathbf{3 0 7 2}\end{array}$ & $\begin{array}{l}\text { Hazard ratio } \\
(95 \% \mathrm{Cl})\end{array}$ & $P$ value \\
\hline $\begin{array}{l}\text { Death, MI, stroke, } \\
\text { major bleeding }\end{array}$ & $8.2 \%$ & $10.4 \%$ & $0.78(0.67-0.93)$ & 0.004 \\
\hline Death, Ml, stroke & $6.3 \%$ & $6.2 \%$ & $1.03(0.84-1.25)$ & 0.79 \\
\hline Major bleeding & $2.4 \%$ & $5.1 \%$ & $0.46(0.35-0.61)$ & $<0.001$ \\
\hline $\begin{array}{l}\text { Early } \mathrm{PCl} \\
(<24 \mathrm{~h} \text { after admission) }\end{array}$ & $N=14 \mid 4$ & $N=1420$ & & \\
\hline $\begin{array}{l}\text { Death, MI, stroke, } \\
\text { major bleeding }\end{array}$ & $7.3 \%$ & $9.5 \%$ & $0.76(0.59-0.98)$ & 0.035 \\
\hline Death, MI, stroke & $5.3 \%$ & $5.4 \%$ & $0.98(0.71-1.34)$ & 0.89 \\
\hline Major bleeding & $2.3 \%$ & $4.9 \%$ & $0.48(0.31-0.72)$ & $<0.001$ \\
\hline
\end{tabular}

Adapted from Mehta et al. ${ }^{22}$

Abbreviations: $\mathrm{MI}$, myocardial infarction; $\mathrm{PCl}$, percutaneous intervention.

( $0 \%$ vs $22 \%, P<0.001)$. An amendment to the OASIS-5 protocol authorized the use of a bolus of UFH at the time of angioplasty to prevent the occurrence of catheter thrombus. This strategy was applicable in 793 OASIS-5 patients under fondaparinux, but was actually applied in only 75 patients, at a median dose of $50 \mathrm{IU} / \mathrm{kg}$, and only one case of catheter thrombus was subsequently observed.

- The mechanism leading to the formation of catheter thrombus under fondaparinux therapy is not clearly elucidated. It is possible that the thrombus formation is facilitated by kallikrein, which can lead to activation of factor XIIa. In vitro studies have shown that activation of factor XIIa can generate thrombin formation after contact with artificial surfaces such as catheters ${ }^{24}$ and that compared with heparin or bivalirudin, fondaparinux is less efficacious in preventing catheter thrombosis. ${ }^{25}$

Table 3 Major bleedings in $\mathrm{PCl}$ patients according to the day after randomization

\begin{tabular}{|c|c|c|c|c|}
\hline $\begin{array}{l}\text { Days after } \\
\text { randomization }\end{array}$ & $\begin{array}{l}\text { Fondaparinux } \\
\mathbf{N}=3105\end{array}$ & $\begin{array}{l}\text { Enoxaparin } \\
\mathbf{N}=\mathbf{3 0 7 2}\end{array}$ & $\begin{array}{l}\text { Relative } \\
\text { risk }\end{array}$ & $P$ value \\
\hline Same day & 0.2 & 0.5 & 0.35 & 0.037 \\
\hline I & 0.7 & 1.7 & 0.40 & $<0.001$ \\
\hline 2 & I.I & 2.8 & 0.40 & $<0.001$ \\
\hline 3 & 1.4 & 3.6 & 0.40 & $<0.001$ \\
\hline 4 & 1.7 & 4.0 & 0.42 & $<0.001$ \\
\hline 5 & 1.8 & 4.3 & 0.42 & $<0.001$ \\
\hline 6 & 2.0 & 4.7 & 0.42 & $<0.001$ \\
\hline 7 & 2.2 & 5.0 & 0.43 & $<0.001$ \\
\hline 8 & 2.4 & 5.0 & 0.45 & $<0.001$ \\
\hline
\end{tabular}

Adapted from Mehta et al. ${ }^{22}$

Abbreviation: $\mathrm{PCl}$, percutaneous intervention.
- The use of an additional bolus of UFH during angioplasty seems to be an effective solution in the case of angioplasty under fondaparinux therapy. However, although the association of different anticoagulants during angioplasty was reported to be safe in terms of the association of bivalirudin and UFH, ${ }^{26}$ the association of enoxaparin with UFH was reportedly associated with an excess of hemorrhagic events, death, or MI in the SYNERGY study. ${ }^{27}$

\section{Confusion between urgent and early PCI}

In the ESC guidelines for NSTE-ACS, three situations are outlined in terms of invasive strategy: elective invasive strategy, early invasive strategy with angioplasty and revascularization within 72 hours of admission, and finally, the so-called "urgent invasive strategy", which is the least common situation, characterized by the persistence of chest pain with ECG changes, hemodynamic instability or severe arrhythmias. This situation requires immediate angiography and urgent angioplasty (Figure 4). The guidelines stipulate that in an urgent invasive strategy, fondaparinux should not be used, whereas it is indicated as the anticoagulant of choice in the other situations. It is thus likely that some confusion exists between "early invasive" and "urgent invasive" strategies, particularly since the ACC-AHA guidelines do not distinguish these two clinical situations..$^{28,29}$

\section{No antidote, but neutralization possible?}

Although fondaparinux has been shown to be safer than UFH and enoxaparin, the fact that it cannot be neutralized remains a source of concern, particularly since its half-life is quite long. 


\begin{tabular}{|c|c|c|c|c|c|}
\hline & $\begin{array}{c}\text { No. (\%) } \\
\text { Unfractionated } \\
\text { Heparin } \\
\end{array}$ & $\begin{array}{l}\text { atients } \\
\text { Fondaparinux }\end{array}$ & $\begin{array}{c}\text { Hazard Ratio } \\
\text { (95\% confidence } \\
\text { Interval) }\end{array}$ & $\begin{array}{c}P \\
\text { Value }\end{array}$ & $\begin{array}{l}P \text { Value for } \\
\text { Interaction }\end{array}$ \\
\hline \multicolumn{6}{|l|}{9 Days } \\
\hline No primary $\mathrm{PCl}$ & $145(10.9)$ & $127(9.5)$ & $0.87(0.69-1.10)$ & 0.25 & \multirow{2}{*}{0.46} \\
\hline Primary $\mathrm{PCl}$ & $78(4.1)$ & $78(4.2)$ & $1.01(0.74-1.38)$ & 0.96 & \\
\hline \multicolumn{6}{|l|}{ Death } \\
\hline No primary $\mathrm{PCl}$ & $113(8.5)$ & $106(7.9)$ & $0.94(0.72-1.22)$ & 0.62 & \multirow{2}{*}{0.74} \\
\hline Primary $\mathrm{PCl}$ & $60(3.2)$ & $60(3.2)$ & $1.01(0.70-1.44)$ & 0.97 & \\
\hline \multicolumn{6}{|l|}{ Reinfarction } \\
\hline No primary $\mathrm{PCl}$ & $43(3.4)$ & 24 (1.9) & $0.55(0.34-0.91)$ & 0.02 & \multirow{2}{*}{0.17} \\
\hline Primary $\mathrm{PCl}$ & $21(1.1)$ & $20(1.1)$ & $0.96(0.52-1.77)$ & 0.90 & \\
\hline \multicolumn{6}{|l|}{30 Days } \\
\hline Death or reinfarction & & & & & \multirow{3}{*}{0.03} \\
\hline No primary $\mathrm{PCl}$ & $184(13.8)$ & $153(11.5)$ & $0.82(0.66-1.02)$ & 0.08 & \\
\hline Primary $\mathrm{PCl}$ & $97(5.1)$ & $115(6.1)$ & $1.20(0.91-1.57)$ & 0.19 & \\
\hline \multicolumn{6}{|l|}{ Death } \\
\hline No primary $\mathrm{PCl}$ & $145(10.9)$ & $128(9.6)$ & $0.88(0.69-1.12)$ & 0.29 & \multirow{2}{*}{0.17} \\
\hline Primary $\mathrm{PCl}$ & $74(3.9)$ & $85(4.5)$ & $1.16(0.85-1.58)$ & 0.36 & \\
\hline \multicolumn{6}{|l|}{ Reinfarction } \\
\hline No primary $\mathrm{PCl}$ & $54(4.3)$ & $33(2.6)$ & $0.60(0.39-0.93)$ & 0.02 & \multirow{2}{*}{0.03} \\
\hline Primary $\mathrm{PCl}$ & $29(1.6)$ & $36(2.0)$ & $1.25(0.77-2.05)$ & $\overline{0.36}$ & \\
\hline \multicolumn{6}{|l|}{$\begin{array}{l}\text { Study end (90-180 days) } \\
\text { Death or reinfarction }\end{array}$} \\
\hline No primary $\mathrm{PCl}$ & $245(19.0)$ & $193(14.9)$ & $0.77(0.64-0.93)$ & 0.008 & \multirow{2}{*}{0.04} \\
\hline Primary $\mathrm{PCl}$ & $143(8.2)$ & $150(8.5)$ & $1.06(0.84-1.33)$ & 0.61 & \\
\hline \multicolumn{6}{|l|}{$\overline{\text { Death }}$} \\
\hline No primary $\mathrm{PCl}$ & $195(15.1)$ & $155(11.9)$ & $0.79(0.64-0.97)$ & 0.03 & \multirow{2}{*}{0.11} \\
\hline Primary $\mathrm{PCl}$ & $1.4(5.9)$ & $107(6.1)$ & $1.04(0.79-1.36)$ & 0.79 & \\
\hline \multicolumn{6}{|l|}{ Reinfarction } \\
\hline No primary $\mathrm{PCl}$ & $75(6.5)$ & $47(4.0)$ & $0.61(0.43-0.88)$ & 0.0097 & \multirow{2}{*}{0.06} \\
\hline Primary $\mathrm{PCl}$ & $53(3.2)$ & $53(3.2)$ & $1.01(0.69-1.48)$ & $\overline{0.95}$ & \\
\hline
\end{tabular}

Figure 3 OASIS-6: Results in stratum 2 based on whether patients underwent primary PCI $(\mathrm{n}=3768)$ or not. Reproduced with permission from Yusuf S, Mehta SR, Chrolavicius S, et al. Effects of fondaparinux on mortality and reinfarction in patients with acute ST-segment elevation mycardial infarction: the OASIS-6 randomized trial. JAMA. 2006;295(I3):1519-1530. ${ }^{16}$ Copyright (C) 2006 American Medical Association.

*Includes all primary PCls in hospital not only for index myocardial infarction.

Abbrivation: $\mathrm{PCl}$, percutaneous coronary Intervention.

The use of recombinant factor VIIa to counteract major bleeding has been described in other types of coagulation disorders. ${ }^{30,31}$ In patients treated with fondaparinux, the use of recombinant factor VIIa (Novo $7^{\circledR}$ ) was studied among 16 healthy volunteers. After injection of $10 \mathrm{mg}$ of fondaparinux, normalization of the endogenous thrombin potential was obtained 2 to 6 hours after administration of $90 \mu \mathrm{g} / \mathrm{kg}$ of factor VIIa, suggesting that there is potential for this formula to be used in case of bleeding under fondaparinux. ${ }^{32}$

\section{Other potential obstacles to the use of fondaparinux}

The factors that determine the choice of anticoagulant in any given situation are manifold, and thus, it is difficult to list exhaustively all the reasons why fondaparinux is or is not used in patients with NSTE-ACS. Nonetheless, it is like that medico-legal and/or economic factors, as well as a generalized reluctance to change, are responsible for the slow uptake of fondaparinux, to the same extent as the scientific reasons. In this context, the main reason why fondaparinux is not used in the United States is probably because it is not approved for use in ACS by the US Food and Drug Administration, despite the scientific evidence in its favor provided by the OASIS- 5 and 6 studies. The increasing use of a radial approach for coronary angiography and angioplasty is an efficacious method of reducing bleeding risk, that probably also minimizes the potential benefit of fondaparinux over heparins. Conversely, the low cost and synthetic nature of 


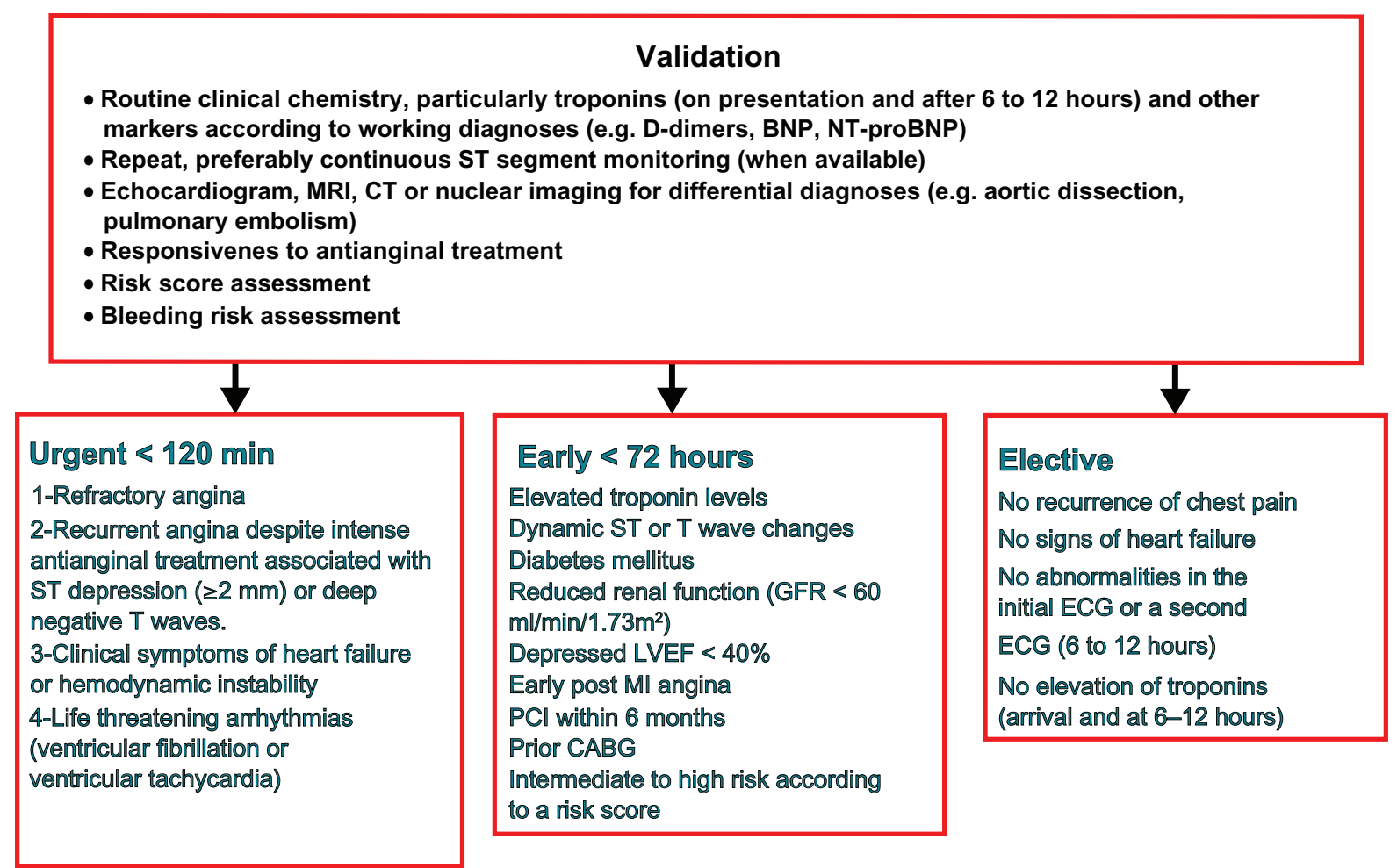

Figure 4 Management Strategy in NEST-ACS according to the Guidelines of the European Society of Cardiology.

fondaparinux are characteristics that should plead highly in its favor. Indeed, the contamination with chondroitin sulphate of tissue extracts used to manufacture heparins, brought to light by a series of fatal adverse reactions in $2008^{33}$ was allegedly voluntary; underlining once again the advantage of synthetic molecules over those fabricated using tissue extracts.

\section{Conclusion}

Fondaparinux is an anticoagulant that presents particular advantages for use in the setting of acute coronary syndromes, and its efficacy and safety have been convincingly demonstrated in two randomized trials that included a huge number of patients across the spectrum of clinical situations represented by ACS. With the exception of primary angioplasty, fondaparinux is as effective as enoxaparin or UFH, but is also associated with a considerable reduction in bleeding complications, and thus, an undeniable net clinical benefit. The rate of use of fondaparinux in routine practice is as yet poorly documented. On the assumption that reluctance to use fondaparinux is unjustified, bearing in mind that European and North American guidelines recommend fondaparinux as the anticoagulant of choice, particularly when there is a high risk of bleeding, and in view of its simplicity of use (single dose, one daily injection, no monitoring), fondaparinux could become one of, if not the most, widely used anticoagulants in ACS. However, there remains the problem of patients with renal dysfunction, who present a high risk of both thrombosis and bleeding, and thus do not qualify for treatment with any of the "new" anticoagulants available.

\section{Disclosure}

The author declares no conflicts of interest.

\section{References}

1. Anderson JL, Adams CD, Antman EM, et al. ACC/AHA 2007 Guidelines for the Management of Patients With Unstable Angina/Non-STElevation Myocardial Infarction-Executive Summary A Report of the American College of Cardiology/American Heart Association Task Force on Practice Guidelines (Writing Committee to Revise the 2002 Guidelines for the Management of Patients With Unstable Angina/NonST-Elevation Myocardial Infarction) Developed in Collaboration with the American College of Emergency Physicians, the Society for Cardiovascular Angiography and Interventions, and the Society of Thoracic Surgeons Endorsed by the American Association of Cardiovascular and Pulmonary Rehabilitation and the Society for Academic Emergency Medicine. J Am Coll Cardiol. 2007;50(7):652-726.

2. Bassand JP, Hamm CW, Ardissino D, et al. Guidelines for the diagnosis and treatment of non-ST-segment elevation acute coronary syndromes. Eur Heart J. 2007;28(13):1598-1660.

3. Cohen M, Demers C, Gurfinkel EP, et al. A comparison of lowmolecular-weight heparin with unfractionated heparin for unstable coronary artery disease. Efficacy and Safety of Subcutaneous Enoxaparin in Non-Q-Wave Coronary Events Study Group. $N$ Engl $J$ Med. 1997;337(7):447-452. 
4. Antman EM, McCabe CH, Gurfinkel EP, et al. Enoxaparin prevents death and cardiac ischemic events in unstable angina/non-Q-wave myocardial infarction. Results of the thrombolysis in myocardial infarction

5. Antman EM, Morrow DA, McCabe $\mathrm{CH}$, et al. Enoxaparin versus unfractionated heparin with fibrinolysis for ST-elevation myocardial infarction. N Engl J Med. 2006;354(14):1477-1488.

6. Ferguson JJ, Califf RM, Antman EM, et al. Enoxaparin vs unfractionated heparin in high-risk patients with non-ST-segment elevation acute coronary syndromes managed with an intended early invasive strategy: primary results of the SYNERGY randomized trial. JAMA. 2004;292(1):45-54.

7. Stone GW, McLaurin BT, Cox DA, et al. Bivalirudin for patients with acute coronary syndromes. N Engl J Med. Nov 23 2006;355(21):2203-2216.

8. Stone GW, Witzenbichler B, Guagliumi G, et al. Bivalirudin during primary PCI in acute myocardial infarction. $N$ Engl $\mathrm{J} \mathrm{Med}$. 2008;358(21):2218-2230.

9. Petitou M, Herault JP, Bernat A, et al. Synthesis of thrombin-inhibiting heparin mimetics without side effects. Nature. 1999;398(6726):417-422.

10. Bauer KA, Eriksson BI, Lassen MR, Turpie AG. Fondaparinux compared with enoxaparin for the prevention of venous thromboembolism after elective major knee surgery. N Engl J Med. 2001;345(18):1305-1310.

11. Eriksson BI, Bauer KA, Lassen MR, Turpie AG. Fondaparinux compared with enoxaparin for the prevention of venous thromboembolism after hip-fracture surgery. $N$ Engl J Med. 2001 Nov 1;345(18): 1298-1304.

12. Vuillemenot A, Schiele F, Meneveau N, et al. Efficacy of a synthetic pentasaccharide, a pure factor Xa inhibitor, as an antithrombotic agent-a pilot study in the setting of coronary angioplasty. Thromb Haemost. 1999;81(2):214-220.

13. Coussement PK, Bassand JP, Convens C, et al. A synthetic factorXa inhibitor (ORG31540/SR9017A) as an adjunct to fibrinolysis in acute myocardial infarction. The PENTALYSE study. Eur Heart J. 2001;22(18):1716-1724

14. Mehta SR, Steg PG, Granger CB, et al. Randomized, blinded trial comparing fondaparinux with unfractionated heparin in patients undergoing contemporary percutaneous coronary intervention: Arixtra Study in Percutaneous Coronary Intervention: a Randomized Evaluation (ASPIRE) Pilot Trial. Circulation. 2005;111(11):1390-1397.

15. Yusuf S, Mehta SR, Chrolavicius S, et al. Comparison of fondaparinux and enoxaparin in acute coronary syndromes. $N$ Engl $\mathrm{J} \mathrm{Med}$. 2006;354(14):1464-1476.

16. Yusuf S, Mehta SR, Chrolavicius S, et al. Effects of fondaparinux on mortality and reinfarction in patients with acute ST-segment elevation mycardial infarction: the OASIS-6 randomized trial. JAMA. 2006;295(13):1519-1530.

17. Van de Werf F, Bax J, Betriu A, et al. Management of acute myocardial infarction in patients presenting with persistent ST-segment elevation: the Task Force on the Management of ST-Segment Elevation Acute Myocardial Infarction of the European Society of Cardiology. Eur Heart J. 2008;29(23):2909-2945.

18. Bassand JP, Hamm CW, Ardissino D, et al. Guidelines for the diagnosis and treatment of non-ST-segment elevation acute coronary syndromes. The Task Force for the Diagnosis and Treatment of Non-ST-Segment Elevation Acute Coronary Syndromes of the European Society of Cardiology. Eur Heart J. 2007;28(13):1598-1660. (TIMI) 11B trial. Circulation. 1999;100(15):1593-1601.

19. Harrington RA, Becker RC, Cannon CP, et al. Antithrombotic therapy for non-ST-segment elevation acute coronary syndromes: American College of Chest Physicians Evidence-Based Clinical Practice Guidelines (8th Edition). Chest. 2008;133(6 Suppl):670S-707S.

20. Schiele F, Meneveau N, Seronde MF, et al. Routine use of fondaparinux in acute coronary syndromes: a 2-year multicenter experience. Am Heart J. 2010;159(2):190-198.

21. Mehta SR, Boden WE, Eikelboom JW, et al. Antithrombotic therapy with fondaparinux in relation to interventional management strategy in patients with ST- and non-ST-segment elevation acute coronary syndromes: an individual patient-level combined analysis of the Fifth and Sixth Organization to Assess Strategies in Ischemic Syndromes (OASIS 5 and 6) randomized trials. Circulation. 2008;118(20):2038-2046.

22. Mehta SR, Granger CB, Eikelboom JW, et al. Efficacy and safety of fondaparinux versus enoxaparin in patients with acute coronary syndromes undergoing percutaneous coronary intervention: results from the OASIS-5 trial. J Am Coll Cardiol. 2007;50(18):1742-1751.

23. Goodman SG, Menon V, Cannon CP, Steg G, Ohman EM, Harrington RA. Acute ST-segment elevation myocardial infarction: American College of Chest Physicians Evidence-Based Clinical Practice Guidelines (8th Edition). Chest. 2008;133(6 Suppl):708S-775S

24. Stief TW. Kallikrein activates prothrombin. Clin Appl Thromb Hemost 2008;14(1):97-98.

25. Maegdefessel L, Buerke M, Schubert S, et al. Comparison of bivalirudin, enoxaparin, and unfractionated heparin in preventing cardiac catheter thrombosis. Results of an in-vitro study. Thromb Haemost. 2008;100(4):693-698.

26. Mehran R, Pocock SJ, Stone GW, et al. Associations of major bleeding and myocardial infarction with the incidence and timing of mortality in patients presenting with non-ST-elevation acute coronary syndromes: a risk model from the ACUITY trial. Eur Heart J. 2009;30(12): 1457-1466.

27. Cohen M, Mahaffey KW, Pieper K, et al. A subgroup analysis of the impact of prerandomization antithrombin therapy on outcomes in the SYNERGY trial: enoxaparin versus unfractionated heparin in nonST-segment elevation acute coronary syndromes. J Am Coll Cardiol. 2006;48(7):1346-1354.

28. Eikelboom J, Guyatt G, Hirsh J. Guidelines for anticoagulant use in acute coronary syndromes. Lancet. 2008;371(9624):1559-1561.

29. Bassand JP, Hamm C. Guidelines for anticoagulant use in acute coronary syndromes. Lancet. 2008;372(9638):532-533; author reply 533-534.

30. Kubisz P, Stasko J. Recombinant activated factor VII in patients at high risk of bleeding. Hematology. 2004;9(5-6):317-332.

31. Haverkamp D, Hutten BA, Buller HR, Gallus AS, Lensing AW, Prins MH. The use of specific antidotes as a response to bleeding complications during anticoagulant therapy for venous thromboembolism. J Thromb Haemost. 2003;1(1):69-73.

32. Bijsterveld NR, Moons AH, Boekholdt SM, et al. Ability of recombinant factor VIIa to reverse the anticoagulant effect of the pentasaccharide fondaparinux in healthy volunteers. Circulation. 2002;106(20): 2550-2554.

33. Kishimoto TK, Viswanathan K, Ganguly T, et al. Contaminated heparin associated with adverse clinical events and activation of the contact system. N Engl J Med. 2008;358(23):2457-2467.

Vascular Health and Risk Management

\section{Publish your work in this journal}

Vascular Health and Risk Management is an international, peerreviewed journal of therapeutics and risk management, focusing on concise rapid reporting of clinical studies on the processes involved in the maintenance of vascular health; the monitoring, prevention and treatment of vascular disease and its sequelae; and the involvement of

\section{Dovepress}

metabolic disorders, particularly diabetes. This journal is indexed on PubMed Central and MedLine. The manuscript management system is completely online and includes a very quick and fair peer-review system, which is all easy to use. Visit http://www.dovepress.com/ testimonials.php to read real quotes from published authors. 